\title{
Microstructure and mechanical properties of Ti/AITiN/Ti-diamondlike carbon composite coatings on steel
}

\author{
Xiaolu Pang, Huisheng Yang, ${ }^{\text {a) }}$ Shijian Shi, Kewei Gao, and Yanbin Wang \\ Department of Materials Physics and Chemistry, University of Science and Technology Beijing, \\ Beijing 100083, China \\ Alex A. Volinsky \\ Department of Mechanical Engineering, University of South Florida, Tampa, Florida 33620
}

(Received 10 December 2009; accepted 21 April 2010)

\begin{abstract}
Ti/AlTiN/Ti-diamondlike carbon (DLC) composite coatings were deposited by midfrequency magnetron sputtering and Hall ion source-assisted deposition on high-speed steel $\mathrm{W}_{18} \mathrm{Cr}_{4} \mathrm{~V}$ substrates. The coating microstructure and mechanical properties, including hardness, elastic modulus, coefficient of friction, and wear properties were investigated by scanning electron microscopy, Raman spectroscopy, scratch and ball-ondisk friction tests, respectively. Fairly smooth composite coating with strong interfacial adhesion and good mechanical properties was produced. The substrate bias increases $s p^{3}$ bonds contents in the DLC layer, thus coating hardness increased from 14 to $24 \mathrm{GPa}$ and elastic modulus from 190 to $230 \mathrm{GPa}$ with the increased substrate bias. Adhesion of interfaces between Ti-DLC and AlTiN layer, AlTiN and the steel substrate decreased with the substrate bias. The coefficient of friction is between 0.10 and 0.15 , except when the substrate bias is $500 \mathrm{~V}$, it is 0.2 . Composite coating wear resistance increased with the substrate bias.
\end{abstract}

\section{INTRODUCTION}

With the coatings technology development, single layer coatings no longer satisfy industrial performance requirements, thus double or multilayered coatings are being developed as a new generation of protective coatings for cutting tools. ${ }^{1-3}$ Some of these have already been applied in selected cases in modern machining techniques such as dry high-speed milling, turning, tapping, and drilling, or when minimal lubrication is required. Machining under dry conditions has been accepted to reduce environmental pollution and the high cost of lubricant recycling along with eliminating the need to maintain complicated lubricating systems in modern cutting and milling machines. Such a trend in machining technology has also been influenced by the development of new hard protective coatings for industrial manufacturing, including established low friction coatings, such as diamondlike carbon (DLC). ${ }^{4,5}$

Amorphous carbon is formed with $s p^{3}$ and $s p^{2}$ carbon bonds. If the amount of hydrogen contained in a film is reduced and the ratio of $s p^{3}$ to $s p^{2}$ is increased, DLC will usually become harder. DLC coatings are amorphous materials deposited at low temperatures and are very smooth. Although coefficient of friction changes with the measurement conditions, it can be as low as 0.1 , or

\footnotetext{
a) Address all correspondence to this author.

e-mail: pangxl@mater.ustb.edu.cn

DOI: $10.1557 / J M R .2010 .0281$
}

even less in air, ${ }^{6-9}$ oil, and water. ${ }^{10}$ Metal-containing diamondlike carbon (Me-DLC) is a DLC film in which metal nanoclusters are dispersed homogeneously, providing a possibility of solving adhesion problems. Metal clusters are remarkably effective for decreasing stress in DLC films. Tribological properties of the Me-DLC in dry sliding wear using a ball-on-disk tribometer have been reported. ${ }^{11,12}$ The average friction coefficient depends strongly on the test duration. ${ }^{13-15}$ The wear rate correlates with both hardness and with the intrinsic nanometer-scale roughness of the Me-DLC. ${ }^{13}$ Such research on friction and sliding characteristics of Me-DLC has already been carried out, ${ }^{16-20}$ and the possibility of nonlubricated sliding has been demonstrated. However, thin film hardness generally decreases with a larger fraction of metal inclusions, and film damage due to abrasion will be more likely than delamination.

AlTiN coating on hardened or austenitic stainless steels has been proven to improve cutting performance in heavy duty machining. These improvements were observed in different cutting operations due to the coating smooth surface, high hardness, and good adhesion. ${ }^{21}$ For low friction applications AlTiN coating can be combined with a Ti-C: $\mathrm{H}$ top layer.

In this work DLC coatings sputtered on hard, wear, and temperature-resistant AlTiN coating deposited on high-speed steel substrates with a Ti interlayer were studied. Coatings microstructure and mechanical properties, including hardness, elastic modulus, friction coefficient, 
and wear properties were investigated by scanning electron microscopy (SEM), Raman spectroscopy, scratch and ball-on-disk friction tests, respectively.

\section{EXPERIMENTAL DETAILS}

Ti/AlTiN/Ti-DLC composite coatings were deposited on high-speed steel $\left(\mathrm{W}_{18} \mathrm{Cr}_{4} \mathrm{~V}\right)$ by a combination of medium frequency magnetron sputtering (Ti/AlTiN) and plasma-enhanced chemical vapor deposition (PECVD) (Ti-DLC). $\mathrm{Ti}$ and metallic compound targets ( $\mathrm{Al} / \mathrm{Ti}$ at.\% ratio $=33: 67$ ) with $99.9 \%$ purity were used. The first $\mathrm{Ti}$ target was used to deposit Ti interlayer between the steel substrate and AlTiN layer to improve adhesion. The second AlTi target was used to deposit the main layers. An ion source was used to enhance ions intensity, and a heater was used to control the chamber temperature. The rotation rate of the substrate holder was $30 \mathrm{rpm}$. The target current was $1 \mathrm{~A}$, the base pressure was $2 \times 10^{-4} \mathrm{~Pa}$, and the flow rate of $99.99 \%$ pure Ar was $45 \mathrm{sccm}$. Nitrogen $\left(\mathrm{N}_{2}\right.$ 99.99\% pure) was used as the reactive gas. After Ti/AlTiN deposition, $\mathrm{C}_{2} \mathrm{H}_{2}$ was introduced into the chamber for Ti-DLC deposition. Detailed deposition parameters are shown in Table I.

Prior to deposition substrates were cleaned in acetone and ethanol for $10 \mathrm{~min}$ sequentially, and were subjected to $10 \mathrm{~min}$ in situ Ar plasma cleaning at a radiofrequency power of $100 \mathrm{~W}$ to remove any contaminants on the substrate surface and to activate the surface. Ti interlayer was deposited on the substrates for 5 min with a direct current of $1 \mathrm{~A}$ and then $\mathrm{N}_{2}$ gas was introduced into the reaction chamber.

Microstructure of Ti/AlTiN/Ti-DLC composite coatings was analyzed by cross-section SEM and Raman spectroscopy. Coatings hardness and Young's modulus were characterized using Hysitron Triboindenter (Minneapolis, $\mathrm{MN}$ ) with a Berkovich diamond indenter tip. Hardness and modulus values presented are an average of 10 or more indents for each test condition.

Adhesion and tribological properties of Ti/AlTiN/ Ti-DLC composite coatings were evaluated by means of a scratch and ball-on-disk tests, respectively, using Universal Micro-Tribometer (UMT; CETR, Campbell, CA) tribometer. The normal load was continuously increased at a rate of $1 \mathrm{~N} / \mathrm{s}$, while the conical diamond tip (120 angle, $200-\mu \mathrm{m}$ tip radius) was moving at a constant velocity of $0.05 \mathrm{~mm} / \mathrm{s}$ for the adhesion test. A GCr15 steel ball was used as a coating wear counterpart in air. Normal load of $10 \mathrm{~N}$ was applied to the coatings surface for $1 \mathrm{~h}$. Circular wear track developed in the coating had a radius of $6 \mathrm{~mm}$, and the ball rotation speed was $600 \mathrm{rpm}$. In the ball-on-disk tests the coating wear volume, $V$, was calculated by approximating the worn volume to a spherical cap. Assuming that the height of the cap is much smaller than the ball radius, the wear volume can be calculated as

$$
V=2 \pi R\left[r^{2} \sin ^{-1}\left(\frac{w}{2 r}\right)-\frac{w}{4}\left(4 r^{2}-w^{2}\right)^{\frac{1}{2}}\right],
$$

where $w$ is the wear scar width measured by optical microscopy, $R$ is the circular wear track radius, and $r$ is the $\mathrm{GCr} 15$ ball radius. ${ }^{22}$

\section{RESULTS AND DISCUSSION}

Figure 1(a) shows an SEM cross-section of the Ti/AlTiN/Ti-DLC composite coatings, including interfaces with the thickness of about $90 \mathrm{~nm}$ for Ti interlayer and $350 \mathrm{~nm}$ for AlTiN interlayer. Several papers demonstrated that a metal layer, $0.5-1.5 \mu \mathrm{m}$ thick helps to accommodate the coating's residual stresses and allows for thicker coatings to be deposited, with significant improvements in toughness, adhesion, and impact resistance. ${ }^{23,24}$ Figure 1(a) also shows a typical columnar microstructure of the Ti interlayer, the AlTiN layer, and a Ti/AlTiN superlattice with an average grain size of about 50-80 $\mathrm{nm}$. Interfaces at Ti/substrate and AlTiN/ DLC layers are clearly defined in Fig. 1(a) with a dense and thin amorphous layer. The top DLC layer is also dense without any defect as the other two interlayers are free of intergranular porosity, cracks, and other defects. Figure 1(b) shows the DLC film deposition rate

TABLE I. Ti/AlTiN/Ti-DLC deposition parameters.

\begin{tabular}{|c|c|c|c|c|c|c|c|c|}
\hline & $\begin{array}{c}\mathrm{Ar} \\
(\mathrm{sccm})\end{array}$ & $\begin{array}{c}\mathrm{N}_{2} \\
(\mathrm{sccm})\end{array}$ & $\mathrm{C}_{2} \mathrm{H}_{2}(\mathrm{sccm})$ & $\begin{array}{l}\text { Ti target } \\
\text { current (A) }\end{array}$ & $\begin{array}{l}\text { AlTi target } \\
\text { current (A) }\end{array}$ & Ion source & $\begin{array}{l}\text { Bias voltage } \\
\text { (V) }\end{array}$ & $\begin{array}{l}\text { Time } \\
(\mathrm{min})\end{array}$ \\
\hline Clear & 45 & $\ldots$ & $\ldots$ & $\ldots$ & $\ldots$ & $\ldots$ & 700 & 10 \\
\hline $\mathrm{Ti}$ & 45 & $\ldots$ & $\ldots$ & 1.0 & $\ldots$ & Current: $8.0 \mathrm{~A}$, & $\ldots$ & 5 \\
\hline AlTiN & 45 & 4 & $\ldots$ & $\ldots$ & 1.0 & $\begin{array}{c}\text { keep } \\
\text { voltage: } 85-90 \mathrm{~V}\end{array}$ & $\ldots$ & 60 \\
\hline Decrease to $60^{\circ} \mathrm{C}$ & $\ldots$ & $\ldots$ & $\ldots$ & $\ldots$ & $\ldots$ & $\ldots$ & $\ldots$ & \\
\hline DLC & 45 & $\ldots$ & $\begin{array}{l}\text { Increase flux from } \\
0 \text { to } 30 \text { in } 15 \mathrm{~min}\end{array}$ & 1.0 & & $\ldots$ & $100 *$ & 15 \\
\hline DLC & 45 & $\ldots$ & 30 & 1.0 & & $\ldots$ & & 35 \\
\hline
\end{tabular}

* Variable parameter. 


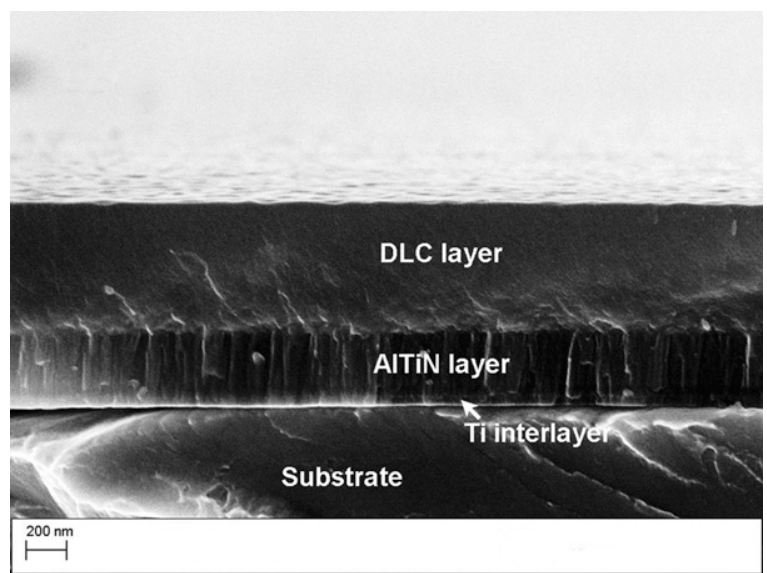

(a)

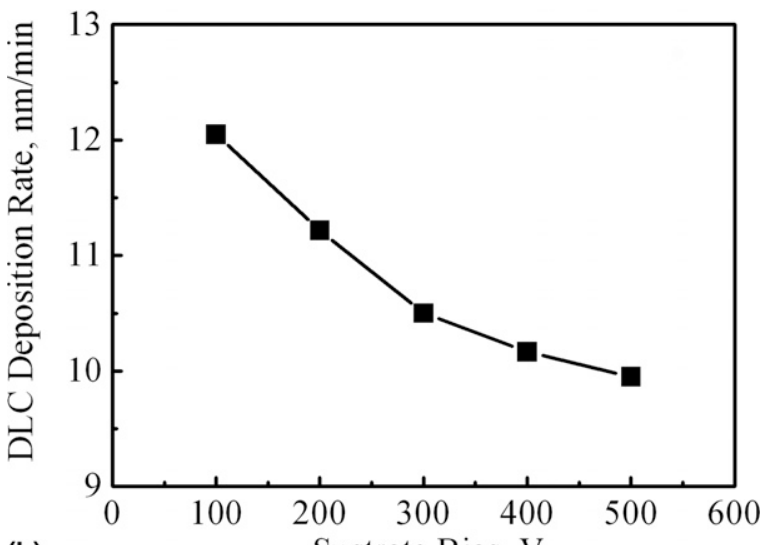

(b)

Sustrate Bias, V

FIG. 1. (a) Cross-section SEM micrograph of Ti/TiAlN/Ti-DLC composite coatings; (b) DLC coating deposition rate dependence on the substrate bias.

TABLE II. Deposition temperature versus substrate bias.

\begin{tabular}{lccccc}
\hline \hline Substrate bias & $100 \mathrm{~V}$ & $200 \mathrm{~V}$ & $300 \mathrm{~V}$ & $400 \mathrm{~V}$ & $500 \mathrm{~V}$ \\
\hline $\begin{array}{c}\text { Deposition } \\
\text { temperature }\end{array}$ & $69.9{ }^{\circ} \mathrm{C}$ & $73.3^{\circ} \mathrm{C}$ & $77.8^{\circ} \mathrm{C}$ & $84.5^{\circ} \mathrm{C}$ & $89.4{ }^{\circ} \mathrm{C}$ \\
\hline \hline
\end{tabular}

dependence on the bias voltage applied to the substrate for the same deposition time, obtained from the SEM cross-sectional micrographs. The deposition rate at low bias is much higher than at high bias. The main reason is a larger number of carbon ions with higher energy, which increases the ion collision probability and the DLC layer becomes denser. With further substrate bias increase, the deposition rate continues to decrease, but at a lower rate, which means that carbon ions deposition and reflection actions are combined. The deposition temperature shows a small increase with the substrate bias as shown in Table II, which was caused by the increased ions bombardment. Higher deposition temperature may affect coating stresses. Coatings' stresses depend on the layer thickness, substrate materials, and deposition temperature. De Hosson ${ }^{25,26}$ showed that the stress in TiN and
AlTiN layers is related to the coating thickness, substrate roughness, and grain size. In our experiments, the deposition parameters of the Ti and AlTiN layer are the same for different samples, therefore the stress levels in the AlTiN layer are the same. However, the substrate bias used for DLC layer deposition is different, resulting in different stress levels in DLC layers produced.

Figures 2(a) and 2(b) show a typical deconvoluted Raman spectra fitted with Gaussians. The value of full width at half-maximum of the $G$ peak $\left(\mathrm{FWHM}_{G}\right)$ and ratio between intensities of the two peaks $I(D) / I(G)$ can be extracted from Raman results, which vary depending on the structure of DLC films. The $\mathrm{FWHM}_{G}$ increases as disorder increases, while clustering decreases. On the other hand, $I(D) / I(G)$ is generally used as a parameter for predicting the $s p^{3}$ content and hardness, a smaller $I(D) / I(G)$ ratio corresponding to a higher $s p^{3}$ content. All Raman spectra show a relatively sharp peak at $\sim 1570 \mathrm{~cm}^{-1}$ and a broader one at $\sim 1380 \mathrm{~cm}^{-1}$, commonly referred to as the $G$ and $D$ bands, respectively. The latter becomes wider and blunter than the former one because the film is hydrogenated and the content of graphite is much higher. The shift of both $G$ or $D$ peaks and changing $I(D) / I(G)$ ratio imply that the size of carbon clusters changes. Generally, with the carbon cluster size decreasing, the peaks shift to the right. In this experiment, the shifts of $G$ and $D$ peaks did not exhibit significant changes, but the value of $I(\mathrm{D}) / I(\mathrm{G})$ decreased. Figure $2(\mathrm{c})$ shows the intensity ratio variations of $I(D) / I(G)$. The value of $I(D) / I(G)$ ratio shows gradual decrease with the substrate bias increase from 4.81 at $100 \mathrm{~V}$ bias to 4.09 at the $500 \mathrm{~V}$ bias, which can be qualitatively descriptive of the increasing $s p^{3}$ bonds content. The carbon cluster size can be calculated using Landford's function ${ }^{27}$ :

$$
I(D) / I(G)=(0.033 \lambda-126) / L_{\mathrm{a}},
$$

where $\lambda$ is the laser wavelength and $L_{\mathrm{a}}$ is the cluster size. On the basis of Eq. (2), the cluster size may show slight increase from 10.3 to $12.1 \AA$ when the value of $I(D) / I(G)$ ratio decreases from 4.81 to 4.09 . In Fig. 2(d), the FWHM $_{G}$ decreases from $95.9 \mathrm{~cm}^{-1}$ at $100 \mathrm{~V}$ bias to $88.5 \mathrm{~cm}^{-1}$ at $500 \mathrm{~V}$ bias. With the increasing bias, the $s p^{2}$ clusters became larger and carbon atoms ordering enhanced.

Figure 3 shows the hardness and elastic modulus of Ti/AlTiN/Ti-DLC composite coatings. The hardness sharply increases at a shallow indentation depth below $50 \mathrm{~nm}$ in Fig. 3(a), and then exhibits a plateau at a larger indentation depth, above $100 \mathrm{~nm}$. The average plateau hardness values are reported in Fig. 3(b) for samples produced with the varying substrate bias. At $100 \mathrm{~V}$ substrate bias composite coating's hardness is about 14.2 $\mathrm{GPa}$ and its elastic modulus is $190 \mathrm{GPa}$. When the substrate bias was increased to $200 \mathrm{~V}$, the hardness increased to about $22 \mathrm{GPa}$ and the elastic modulus to 

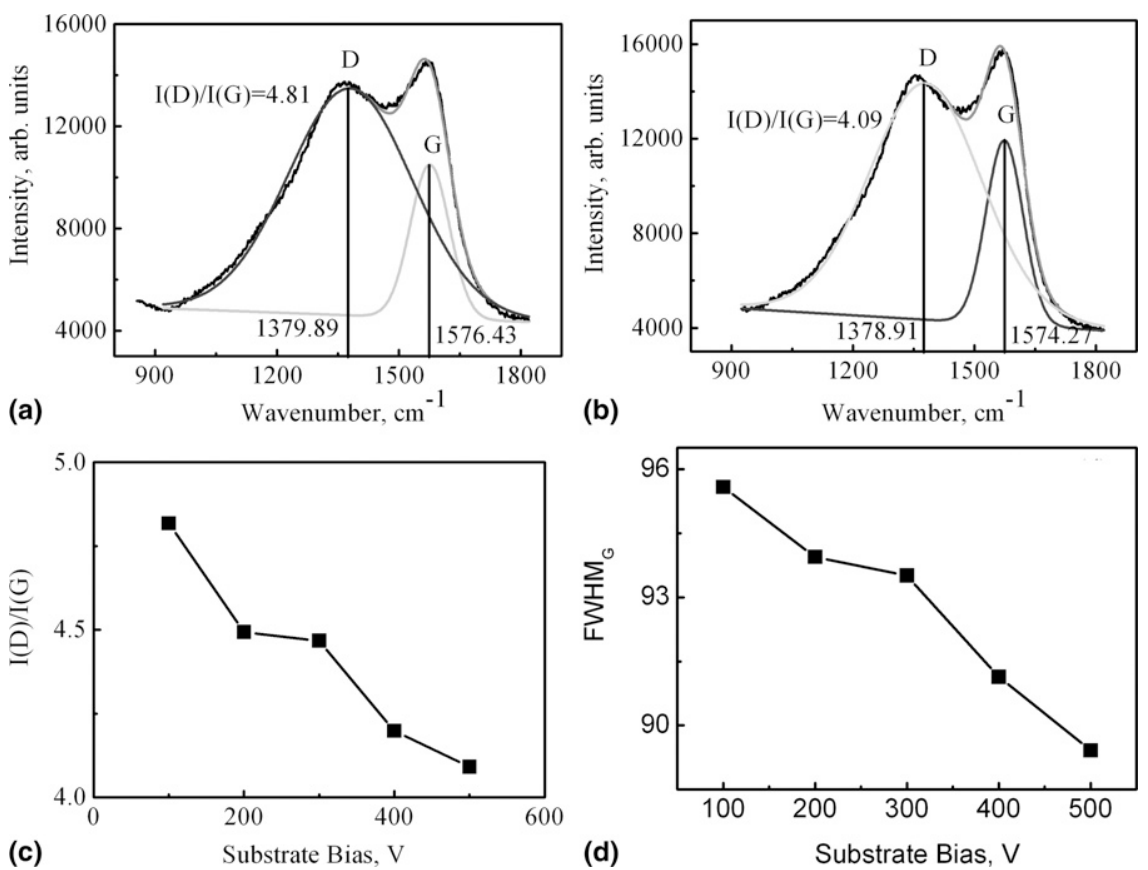

FIG. 2. Raman spectra of DLC layer deposited with different substrate bias: (a) $100 \mathrm{~V}$; (b) $500 \mathrm{~V}$; (c) ratio of $I(D) / I(G)$ at different bias; (d) $\mathrm{FWHM}_{G}$ at different bias.

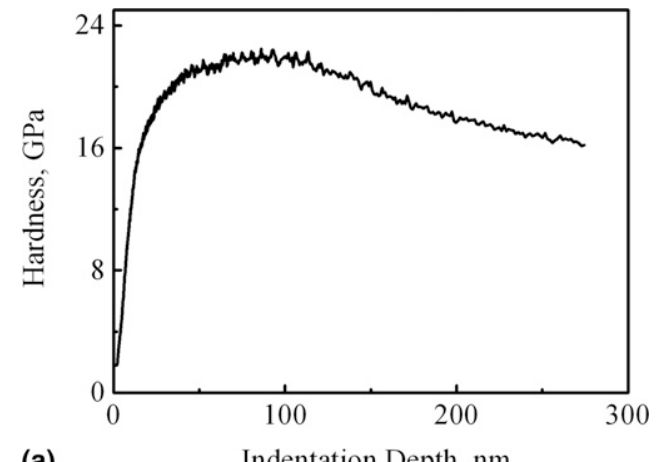

(a)

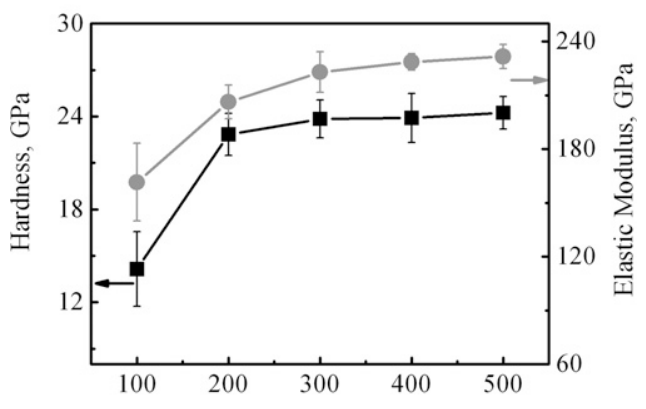

(b)

Substrate Bias, V

FIG. 3. Hardness of composite coatings as a function of (a) indentation depth for $200 \mathrm{~V}$ substrate bias sample and (b) substrate bias.

$210 \mathrm{GPa}$, which is a significant change compared with the $100 \mathrm{~V}$ substrate bias values. However, the hardness and elastic modulus show a slight increase to 24 and $230 \mathrm{GPa}$, respectively, at $500 \mathrm{~V}$ substrate bias. In the composite coatings system, the hardness of composite coatings is in the range between the hardness of different layers. The interlayer AlTiN makes a contribution to the composite hardness, but the experimental parameters of depositing AlTiN and Ti layer are the same for these samples, thus the DLC layer effects the hardness of composite coatings. There are two reasons for this change. First, with the substrate bias increasing from 100 to $200 \mathrm{~V}$ the deposition rate decreases and the composite coatings become much denser. The density of DLC films increases with $s p^{3}$ bonds content in all kinds of amorphous carbon films, which was discussed by Ferrari ${ }^{28}$ and Robertson. ${ }^{29}$ X-ray reflectivity experiments were performed on select samples deposited at 100 and $300 \mathrm{~V}$ bias and show that the critical angle increased from $0.223^{\circ}$ to $0.230^{\circ}$, corresponding with the density of DLC films increasing from 1.18 to $1.25 \mathrm{~g} \cdot \mathrm{cm}^{-3}$, indicating that DLC films deposited at higher bias are denser. The deposition rate does not change significantly with further substrate bias increase, as seen in Fig. 1(b). Second, the $I(D) / I(G)$ ratio decreases with the increasing bias, which can be qualitatively descriptive of $s p^{3}$ bonds content increasing with the substrate bias, so that hardness and elastic modulus show corresponding increases.

The adhesion is one of the most important coating properties, and can be assessed with the scratch test. However, the problem with this method is defining the critical lateral and normal forces. Figure 4(a) shows the lateral and normal forces change with time during a typical scratch test. The critical lateral load is easily identified from the slope variations. The normal force was increased linearly with time during the scratch testing, so it was easily calculated at the critical coating 


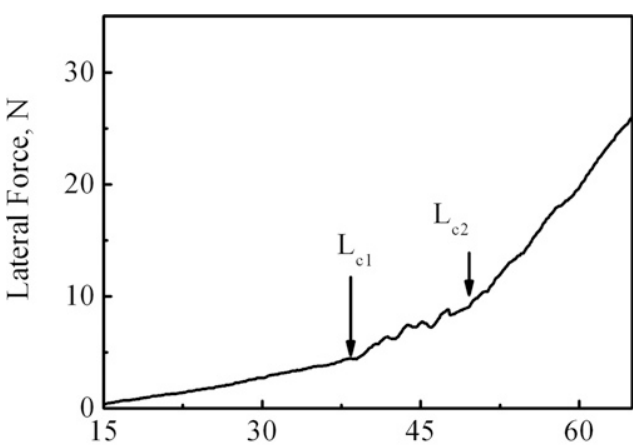

(a)

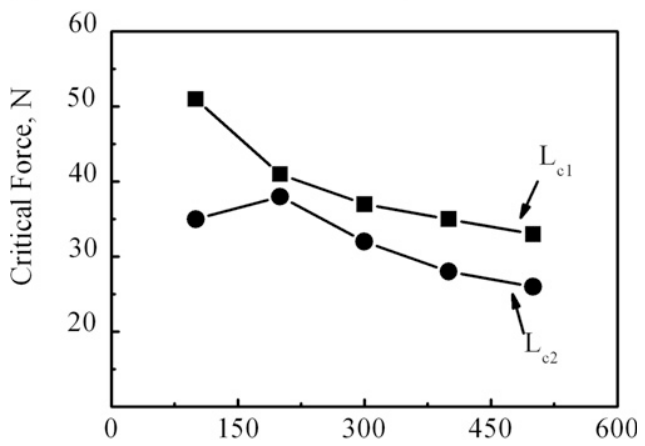

(b)

Substrate Bias, V

FIG. 4. (a) Schematic diagram of critical lateral force change determination for the coating failure during the scratch test; (b) scratch test critical normal force as a function of the substrate bias voltage.

delamination point. $L_{\mathrm{c} 1}$ and $L_{\mathrm{c} 2}$ are the critical points of DLC/AlTiN and coating/substrate interfacial failures, respectively. Figure 4(b) shows the critical normal load of interfacial failures as functions of the substrate bias. With the increasing substrate bias the critical normal load decreased, which may be caused by the coating intrinsic stresses and thermal stresses caused by deposition and temperature changes. The critical normal load also decreased because of the lower film thickness. Corresponding discussion relates to Fig. 1. During sputter deposition ions energy increases with the substrate bias, causing a temperature rise, leading to higher residual stresses after cooling to room temperature. This effect deteriorated the adhesion strength of the coatings at higher substrate bias. The challenge lies in developing a method to produce these coatings with a high hardness and wear resistance, while at the same time not sacrificing adhesion strength. This challenge can be solved by using a proper metallic interlayer and optimizing its microstructure and thickness.

Figure 5 shows the friction coefficient of Ti/AlTiN/TiDLC composite coatings at different substrate bias. The friction coefficient is about 0.1 at 100 and $200 \mathrm{~V}$ bias. With the substrate bias increasing to 300 and $400 \mathrm{~V}$, the friction coefficient values show a slight increase to 0.12 , but when the substrate bias was increased to $500 \mathrm{~V}$, the friction coefficient increased to about 0.2 . This increase

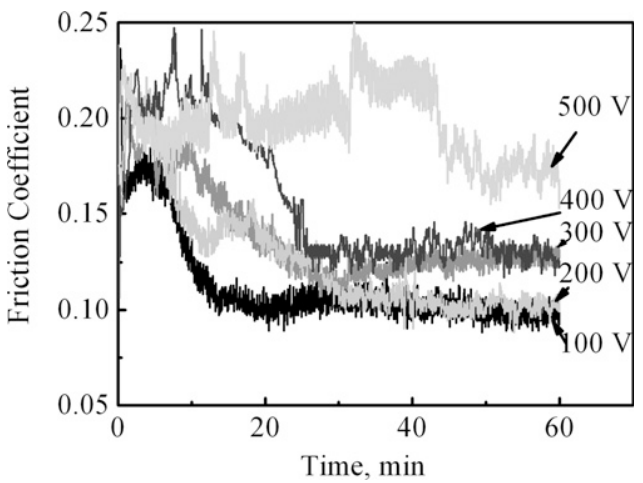

FIG. 5. Friction coefficient of Ti/AlTiN/Ti-DLC composite coatings at different substrate bias.

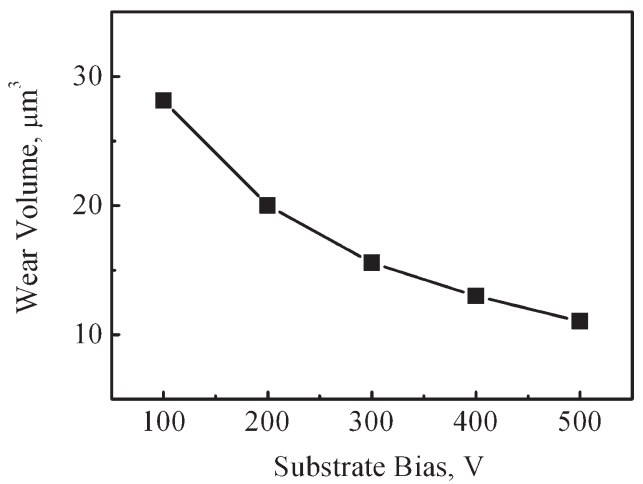

FIG. 6. Wear volume loss as a function of the substrate bias.

can be explained by higher content of $s p^{3}$ bonding and larger cluster size. The value of friction coefficient shows a slight decrease with the increased tribological testing time at 400 and $500 \mathrm{~V}$ bias, which was caused by the transformation of $s p^{3}$ structure to a graphitelike $s p^{2}$ structure on the sliding contact surface. The graphitic structure is well known to be responsible for the low friction coefficient of DLC films. ${ }^{30}$ Indeed, since graphite easily shears the structure promotes friction reduction. Hydrogen incorporation led to an improvement of the sliding behavior with a decrease in the friction coefficient. For most of the PECVD DLC films, hydrogen content is in the range of 20 to 40 at. $\% .^{28}$ The friction coefficient shows a slight increase with the DLC layer bias, possibly corresponding to hydrogen content decrease in our experiments.

A ball-on-disk test was used to obtain coatings friction properties by measuring the lateral force and wear resistance by assessing the change in the wear scar dimensions during sliding contact. The wear volume loss was calculated using Eq. (1), and Fig. 6 shows the wear volume loss as a function of the substrate bias. The wear volume loss gradually decreases from 28.1 to $11.0 \mu \mathrm{m}^{3}$ with the substrate bias increase from 100 to $500 \mathrm{~V}$, but the wear resistance is much higher for the higher bias, since the wear resistance usually scales with hardness 


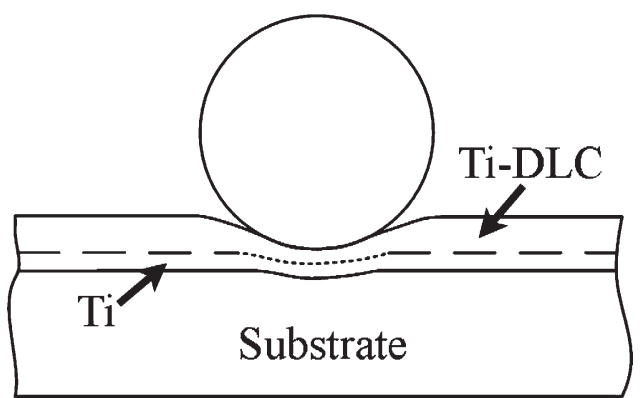

(a)

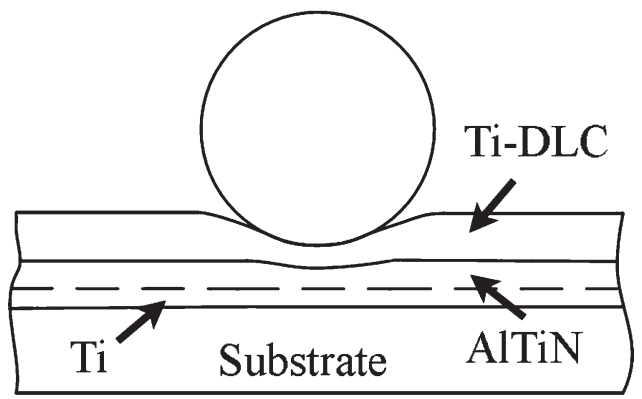

(b)

FIG. 7. Schematic diagram of deformation under wear or scratch test for (a) Ti/Ti-DLC and (b) Ti/AlTiN/Ti-DLC coatings.

and elastic modulus. Many experts ${ }^{31-33}$ reported that coatings' and films' tribological and wear properties depend on the ratio parameters $H / E$ and $H^{2} / E^{3}$, which are more important than the hardness alone. In this case the $H / E$ and $H^{2} / E^{3}$ parameters increase with the substrate bias increase from 110 to $500 \mathrm{~V}$ and indicate that the resistance to plastic deformation is enhanced with the recovery of elastic deformation, ${ }^{31}$ which leads to improved tribological and wear properties. The results shown in Figs. 5 and 6 are consistent with this argument.

In this composite coating, the AlTiN interlayer effects on the adhesion and tribological properties can be related to Fig. 7, which shows schematic diagrams of deformation under wear or scratch tests of $\mathrm{Ti} / \mathrm{Ti}-\mathrm{DLC}$ and Ti/AlTiN/Ti-DLC coatings. Comparing Figs. 7(a) and 7(b), the deformation mechanism is different when the same load is applied on the wear test ball or on the scratch tip because the AlTiN layer is much harder than the substrate. With the gradual increasing hardness away from the substrate, deformation stresses can be effectively released in different layers, therefore the high wear resistance and adhesion can be expected in the Ti/AlTiN/ Ti-DLC composite system.

\section{CONCLUSIONS}

Ti/AlTiN/Ti-DLC composite coatings and interfaces were investigated using SEM, and have columnar grain size of about $50 \mathrm{~nm}$. All interfaces were clearly observed, and the coating layers are dense. $S p^{2}$ and $s p^{3}$ bonds were identified by Raman spectroscopy in the top DLC layer.
$S p^{3}$ bonds contents increased with the substrate bias. Coatings hardness varies from 14 to $24 \mathrm{GPa}$ and elastic modulus varies from 190 to $230 \mathrm{GPa}$, affected by the substrate bias. Scratch testing was used to assess the adhesion of DLC/AlTiN and coatings/substrate interfaces, which was degraded by increased substrate bias. The coefficient of friction is between 0.10 and 0.15 , except for the 0.2 value at $500 \mathrm{~V}$ substrate bias. The ball-on-disc test shows that the wear resistance of coatings increases with increased substrate bias.

\section{ACKNOWLEDGMENTS}

This work was supported by China State Key Lab of Advanced Metals and Materials and Nature Science Foundation of China (No. 51001013). Alex A. Volinsky would like to acknowledge National Science Foundation (NSF) support (CMMI-0600266).

\section{REFERENCES}

1. F-R. Weber, F. Fontaine, M. Scheib, and W. Bock: Cathodic arc evaporation of $(\mathrm{Ti}, \mathrm{Al}) \mathrm{N}$ coatings and $(\mathrm{Ti}, \mathrm{Al}) \mathrm{N} / \mathrm{TiN}$ multilayercoatings correlation between lifetime of coated cutting tools, structural and mechanical film properties. Surf. Coat. Technol. 177/178, 227 (2004).

2. L.A. Dobrzański and K. Gołombek: Structure and properties of the cutting tools made from cemented carbides and cermets with the TiN + mono-, gradient- or multi(Ti, Al, Si)N + TiN nanocrystalline coatings. J. Mater. Process. Technol. 164/165, 805 (2005).

3. W.D. Fan, X. Chen, K. Jagannadham, and J. Narayan: Diamondceramic composite tool coatings. J. Mater. Res. 9, 2850 (1994).

4. X. Li and B. Bhushan: Development of a nanoscale fatigue measurement technique and its application to ultrathin amorphous carbon coatings. Scr. Mater. 47, 473 (2002).

5. T. Takeno, T. Sugawara, H. Miki, and T. Takagi: Deposition of DLC film with adhesive W-DLC layer on stainless steel and its tribological properties. Diamond Relat. Mater. 18, 1023 (2009).

6. M. Kano: Super low friction of DLC applied to engine cam follower lubricated with ester-containing oil. Tribol. Int. 39, 1682 (2006).

7. J. Noshiro, S. Watanabe, T. Sakura, and S. Miyake: Friction properties of co-sputtered sulfide/DLC solid lubricating films. Surf. Coat. Technol. 200, 5849 (2006).

8. E. Konca, Y.T. Cheng, and A.T. Alpas: Dry sliding behaviour of non-hydrogenated DLC coatings against $\mathrm{Al}, \mathrm{Cu}$ and $\mathrm{Ti}$ in ambient air and argon. Diamond Relat. Mater. 15, 939 (2006).

9. A. Erdemir, O.L. Eryilmaz, I.B. Nilufer, and G.R. Fenske: Synthesis of superlow-friction carbon films from highly hydrogenated methane plasmas. Surf. Coat. Technol. 133/134, 448 (2000).

10. R.P.C.C. Statuti, P.A. Radi, L.V. Santos, and V.J. Trava-Airoldi: A tribological study of the hybrid lubrication of DLC films with oil and water. Wear 267, 1208 (2009).

11. T. Michler and C. Siebert: Abrasive wear testing of DLC coatings deposited on plane and cylindrical parts. Surf. Coat. Technol. 163/164, 546(2003).

12. Y.T. Pei, X.L. Bui, X.B. Zhou, and J.Th.M. De Hosson: Tribological behavior of W-DLC coated rubber seals. Surf. Coat. Technol. 202, 1869 (2008).

13. S.J. Harris, A.M. Weiner, and W-J. Meng: Tribology of metalcontaining diamond-like carbon coatings. Wear 211, 208 (1997). 
14. T.W. Scharf, J.A. Ohlhausen, D.R. Tallant, and S.V. Prasad Mechanisms of friction in diamondlike nanocomposite coatings. J.Appl. Phys. 101, 063521 (2007).

15. J. Takadoum, H. Houmid Bennani, and M. Allouard: Friction and wear characteristics of TiN, TiCN and diamond-like carbon films. Surf. Coat. Technol. 88, 232 (1997).

16. W.H. Kao, Y.L. Su, and S.H. Yao: Tribological property and drilling application of $\mathrm{Ti}-\mathrm{C}: \mathrm{H}$ and $\mathrm{Cr}-\mathrm{C}: \mathrm{H}$ coatings on high-speed steel substrates. Vacuum 80, 604 (2006).

17. K. Bewilogua, C.V. Cooper, C. Specht, J. Schröder, R. Wittorf, and M. Grischke: Effect to target material on deposition and properties of metal-containing DLC (Me-DLC) coatings. Surf. Coat. Technol. 127, 224 (2000).

18. C. Strondl, G.J. van der Kolk, T. Hurkmans, W. Fleischer, T. Trinh, N.M. Carvalho, and J.Th.M. de Hosson: Properties and characterization of multilayers of carbides and diamond-like carbon. Surf. Coat. Technol. 142/144, 707 (2001).

19. C. Strondl, N.M. Carvalho, J.Th.M. De Hosson, and G.J. van der Kolk: Investigation on the formation of tungsten carbide in tungsten-containing diamond-like carbon coatings. Surf. Coat. Technol. 162, 288 (2003).

20. W.H. Kao, Y.L. Su, S.H. Yao, and H.C. Huang: Optimizing the tribological properties and high-speed drilling performance of $a$ C:H coatings via nitrogen addition. Surf. Coat. Technol. 204, 1277 (2010).

21. M. Arndt and T. Kacsich: Performance of new AlTiN coatings in dry and high speed cutting. Surf. Coat. Technol. 163/164, 674 (2003).

22. X. Pang, K. Gao, and A.A. Volinsky: Microstructure and mechanical properties of chromium oxide coatings. J. Mater. Res. 22, 3531 (2007).
23. G.S. Kim, S.Y. Lee, J.H. Hahn, B.Y. Lee, J.G. Han, J.H. Lee, and S.Y. Lee: Effects of the thickness of Ti buffer layer on the mechanical properties of TiN coatings. Surf. Coat. Technol. 171, 83 (2003).

24. X. Pang, K. Gao, H. Yang, L. Qiao, Y. Wang, and A.A. Volinsky: Interfacial microstructure of chromium oxide coatings. Adv. Eng. Mater. 9.594 (2007).

25. N.J.M. Carvalho, E. Zoestbergen, B.J. Kooi, and J.Th.M. De Hosson: Stress analysis and microstructure of PVD monolayer TiN and multilayerTiNy(Ti,Al)N coatings. Thin Solid Films 429, 179 (2003).

26. N.J.M. Carvalho and J.Th.M. De Hosson: Deformation mechanisms in $\mathrm{TiN} /(\mathrm{Ti}, \mathrm{Al}) \mathrm{N}$ multilayers underdepth-sensing indentation. Acta Mater. 54, 1857 (2006).

27. W.A. Landford and M.J. Rand: The hydrogen content of plasmadeposited silicon nitride. J. Appl. Phvs. 49, 2473 (1978).

28. C. Casiraghi, A.C. Ferrari, and J. Robertson: Raman spectroscopy of hydrogenated amorphous carbons. Phvs. Rev. B 72, 085401 (2005).

29. J. Robertson: Diamond-like amorphous carbon. Mater. Sci. Eng., $R$ 37, 129 (2002).

30. C. Jaoul, O. Jarry, P. Tristant, T. Merle-Méjean, M. Colas, C. Dublanche-Tixier, and J.M. Jacquet: Raman analysis of DLC coated engine components with complex shape: Understanding wear mechanisms. Thin Solid Films 518, 1475 (2009).

31. D. Galvan, Y.T. Pei, and J.Th.M. De Hosson: Deformation and failure mechanism of nano-composite coatings under nanoindentation. Surf. Coat. Technol. 200.6718 (2006).

32. A. Leyland and A. Matthews: Design criteria for wear-resistant nanostructured and glassy-metal coatings. Surf. Coat. Technol. 177/178, 317 (2004).

33. E. Zoestbergen, N.J.M. Carvalho, and J.Th.M. De Hosson: Stress state of TiN/TiAlN PVD multilayers. Surf. Eng. 17.29 (2001). 